\title{
A Expansão Hoteleira em Santo André
}

\section{The Hotels Sector Growth in Santo André, Brazil}

\author{
Maria de Lourdes Peixoto Xavier ${ }^{1}$ \\ Luis Paulo Bresciani ${ }^{2}$
}

\begin{abstract}
Resumo
O presente artigo busca identificar os fatores que possibilitaram a expansão hoteleira na região do Grande ABC, e em especial na cidade de Santo André, bem como analisar as articulações entre o poder público e a iniciativa privada que influenciaram na definição dos investimentos realizados por determinadas cadeias hoteleiras. $\mathrm{O}$ argumento aponta para a relevância das estratégias adotadas por uma liderança política inovadora na cidade de Santo André, que resultaram na instalação de quatro novos empreendimentos hoteleiros e aumentaram a perspectiva de crescimento do turismo de negócios na região.
\end{abstract}

Palavras-chave: turismo de negócios; hotéis; hotéis em Santo André; hotéis e políticas públicas; projeto Eixo Tamanduatehy.

\begin{abstract}
This study intends to identify the main factors that made possible the hotels' complex growth in the Great $A B C$ region and especially in the city of Santo André, as well as to analyze the relationship between the public management and the private sector and its influences on the investment decision made by specific hotel chains. We argue that relevant strategies adopted for an innovative political leadership in Santo André, that had the outcome of four new hotels established in its restructured central area, and strongly increased the perspective of business-oriented growth for the tourism activity in the region.
\end{abstract}

Keywords: business-oriented tourism; hotels; Santo André's hotels; hotels and public policy; Tamanduatehy Axle project.

\footnotetext{
${ }^{1}$ Mestre em Administração pela Universidade Municipal de São Caetano do Sul, Professora da Faculdade Editora Nacional e Universidade Municipal de São Caetano do Sul (IMES). E-mail: mlxavier-752@uol.com.br

2 Doutor em Política Cientifica e Tecnológica pela Unicamp, Professor do Programa de Mestrado em Administração da Universidade Municipal de São Caetano do Sul (IMES) e secretário de desenvolvimento econômico e ação regional da prefeitura de Santo André. E-mail: lpb3@ig.com.br
} 


\section{Introdução}

O presente artigo tem sua origem na observação da expansão hoteleira na cidade de Santo André, a partir de uma pesquisa exploratória, em que se buscou identificar os fatores que contribuíram para que empreendedores hoteleiros identificassem aquela cidade como um próspero mercado. Ao mesmo tempo, procurou-se analisar a articulação entre sociedade civil, tecido empresarial e a esfera governamental no esforço integrado para tornar a região mais atrativa aos investimentos, fortalecendo a diversificação da atividade econômica regional.

Embora a Região do Grande $\mathrm{ABC}$ apresente relevantes indicadores populacionais e econômicos, contribuindo fortemente com geração de receita para o Estado de São Paulo, viveu em alguma medida à margem da capital paulista, especialmente no que diz respeito às atividades no campo do comércio e dos serviços. Nesse sentido, o artigo aborda o desenvolvimento regional sob a ótica do turismo, focalizando a expansão hoteleira na cidade de Santo André, onde anteriormente havia uma série de restrições para que se construíssem empreendimentos hoteleiros verticais. A partir de iniciativas do poder público e do setor privado, foram se abrindo as possibilidades para o projeto e a construção de quatro novos e modernos hotéis na cidade, melhorando assim, a condição de recepção e hospedagem dos visitantes, bem como abrindo perspectivas para o turismo de negócios na cidade e região.

A pesquisa original partiu de um estudo exploratório e de caráter descritivo, realizado com base em pesquisa documental e entrevistas, tendo os gestores hoteleiros e do poder público como sujeitos. A análise focalizou, portanto, os depoimentos colhidos em entrevistas pautadas por um roteiro estruturado de questões, além dos documentos coletados. O argumento central destaca o papel de uma importante liderança política da cidade de Santo André na condução do processo de reestruturação urbana e econômica do município, bem como a coerência entre a implantação e expansão de uma atividade hoteleira moderna face à concepção e execução do projeto denominado Eixo Tamanduatehy. Ao mesmo tempo, destaca a importância de um melhor diálogo e interação entre setor público e iniciativa privada, visando uma melhor integração dos hotéis à dinâmica sócio-econômica do município.

$\mathrm{O}$ artigo está composto por quatro tópicos que se seguem à presente introdução. $\mathrm{O}$ segundo item traz uma síntese do referencial teórico pertinente, seguido de uma descrição mais detalhada da metodologia de pesquisa; a sessão quatro apresenta o estudo de caso sobre a expansão hoteleira na cidade de Santo André, antecedendo às principais conclusões e considerações finais. 


\section{Referencial Teórico}

A instalação das indústrias no Grande $\mathrm{ABC}$ deu-se inicialmente ao longo do principal meio de transporte existente, a ferrovia. A estrada de ferro, de grande importância na criação e crescimento da cidade de Santo André, foi construída pela companhia inglesa São Paulo Railway na segunda metade do século XIX, entre 1860 e 1868, próxima ao Rio Tamanduateí. O distrito de Santo André, criado em 1910, tinha seu núcleo urbano junto à estação ferroviária e ao longo da ferrovia, foram formando-se o que Sakata (2006) denomina de "povoadosestação", que eram pequenas vilas residenciais e comerciais. Destas vilas surgiram as cidades de São Caetano do Sul, Santo André (anteriormente denominada como estação São Bernardo) e Ribeirão Pires.

Embora estas cidades quase fossem fundidas à capital, segundo Langenbuch (1971), ainda se tratava de um subúrbio do ponto de vista político-administrativo. A partir da década de 1930, com as transformações estruturais características do Estado Novo (1937), as expansões das indústrias tornaram-se um fato. Em 1937 já era grande o número de empresas instaladas no $\mathrm{ABC}$ e a região já tomava forma de centro industrial, com sua economia estruturada nos complexos químico e metal-mecânico, atividades que tiveram grande incentivo nos anos de 1950, favorecendo assim um crescimento de forma desordenada e concentradora, marcado por muitas desigualdades.

Na década de 1950, a utilização da ferrovia já se encontrava debilitada e a fabricação de automóveis e caminhões se combina à construção de estradas, auxiliando e aumentando a vazão dos produtos e a circulação de pessoas. A construção da Via Anchieta, em 1947, foi um grande marco nas mudanças estruturais da região, demarcando o Grande $\mathrm{ABC}$ como ponto estratégico entre o Porto de Santos e a cidade de São Paulo. Pode-se dizer, no entanto, que a maior expansão ocorreu a partir da década de 1950, quando o $\mathrm{ABC}$ paulista passou a concentrar o primeiro e ainda hoje importante cluster da indústria automobilística implantada no país, como ressaltam Bruno, Felipe e Denaldi (2006).

Segundo Klink (2001), o modelo de substituição das importações, acoplado à política de incentivos aos investimentos estrangeiros e à importação de tecnologia estrangeira, foi decisivo para a instalação da cadeia automobilística no Grande ABC. A presença do capital estrangeiro e estatal era certa, porém, a participação das empresas nacionais era pouco representativa, visto que a tecnologia também era trazida pelas empresas de capital estrangeiro e com isto não se criava uma expertise nacional; uma relativa exceção seria a 
nascente indústria de autopeças daquele mesmo período, como nota Addis (1999). Na década de 1970, a economia nacional e também a regional estavam estruturadas basicamente pelo capital estrangeiro, o que, na maioria das vezes, determinava a produção e não mantinha suas decisões no país e sim na matriz, que concentrava o processo de tomada de decisões, ainda de acordo com Klink (2001).

Em meio a esse processo acelerado de industrialização, o Estado de São Paulo apresenta intenso movimento urbano, a rigor iniciado no final do século XIX e que persiste até a década de 1970; a grande concentração se daria no que conhecemos hoje como a Região Metropolitana de São Paulo, tendo o Grande ABC como parte. A cidade de Santo André atingiria, em 1970, o status de segunda unidade populacional do estado de São Paulo, sendo depois ultrapassada por São Bernardo do Campo em número de empresas, especialmente pela mudança do principal vetor de atividade econômica, que deixa de ser a ferrovia para concentra-se nas rodovias Anchieta, e posteriormente a Imigrantes.

A partir da década de 1970, alguns fatores influenciaram para que houvesse a diminuição da concentração industrial na Região Metropolitana de São Paulo (RMSP) em favor do interior do Estado de São Paulo ou para o restante do Brasil. Esta desconcentração e interiorização da atividade econômica e da população, conforme Klink (2001), já vinha se revelando nas décadas de 1970 e 1980. Na visão de Uvinha (2003), além destes fatores, há ainda os problemas de congestionamento, falta de espaço para expansão e uma atividade mais relevante dos sindicatos de trabalhadores, que teriam contribuído para a perda de atratividade em relação a outras localidades no estado e no país. Este período também, segundo Klink (2001), foi marcado pela concorrência territorial entre os estados e municípios do Brasil na atração de novos estabelecimentos, através da chamada queda fiscal.

Houve queda acentuada, que chegou a cerca de $30 \%$ dos empregos industriais em todo o país, entre 1989 e 1999, como aponta Sabóia (2001); evidentemente, os estados e localidades com as maiores bases instaladas seriam também aqueles mais afetados, dentre eles o Grande ABC. No entanto, ainda para Nobre (2000), enquanto o setor secundário apresentava taxas declinantes de emprego, o setor terciário aumentava sua participação, absorvendo parte da força de trabalho industrial. Enquanto a perda de emprego em São Paulo no período de 19881997, segundo Sakata (2006), foi de 1,94\% e na região metropolitana de São Paulo foi de 9,14\%, no Grande ABC a perda foi de $14,05 \%$, um índice alarmante. 
Com a saída de muitas empresas, a região do Grande $\mathrm{ABC}$ poderia ver muito de sua arrecadação cair e, embora houvesse esta evasão, o Produto Interno Bruto - PIB, especificamente de Santo André, não sofria queda constante desde a década de 1980. Essa reestruturação teve impacto na Região do Grande $\mathrm{ABC}$ e também sobre o Estado de São Paulo, onde a partir da década de 1990, os serviços foram os responsáveis pelos investimentos, inclusive investimentos estrangeiros, principalmente devido às privatizações.

A área em torno do Rio Tamanduateí e ao longo da ferrovia ficou estagnada e desestruturada durante muitos anos, sendo que visivelmente havia a necessidade de ocupar, de alguma maneira as áreas inativas. Diante da necessidade de uma reorganização espacial desta região, em 1998 a Prefeitura de Santo André lançou o Projeto Eixo Tamanduatehy, que seria um esforço significativo de urbanismo includente, com participação cidadã, desenvolvimento econômico e inclusão social.

\section{Metodologia}

A pesquisa exploratória é toda aquela que busca constatar algo num organismo ou num fenômeno e neste estudo de caso teve como objetivo analisar a expansão hoteleira na cidade de Santo André. Como a pesquisa envolveu investigação e aprofundamento de estudos sobre um único objeto, a cidade de Santo André, determina-se que esta é classificada como exploratória, sendo o seu delineamento o estudo de caso único.

Os sujeitos da pesquisa deste estudo foram divididos em dois grupos:

a) Na iniciativa privada, foram considerados os representantes dos hotéis instalados na cidade de Santo André, responsáveis pelas implantações dos estabelecimentos Plaza Mayor, Quality, Mercure e Íbis; procurando analisar a motivação do investimento, as ações e o posicionamento estratégico, perspectivas futuras. Bem como identificar os fatores que contribuíram para a implantação nesta região e, especificamente, na cidade de Santo André;

b) Iniciativa pública, por meio dos gestores públicos da cidade, buscando questionar e apresentar os programas e políticas públicas relacionadas às estratégias de desenvolvimento local, bem como às ações com foco no conceito de desenvolvimento da hospitalidade.

A análise dos resultados foi elaborada por meio do confronto entre os dados primários e secundários obtidos em campo. 


\section{A Expansão da Hotelaria na Cidade de Santo André}

Em Santo André, na década de 1950, existia um grande hotel chamado Hotel Restaurante Cavalo Branco, que atuava com duas unidades, a principal sediada à Avenida 15 de Novembro, e uma filial situada à Rua Bernardino de Campos, ambas em Santo André. A sede foi construída em um prédio de quatro andares, tendo seu pavimento térreo utilizado como salão de baile, e atendia aos moradores em bailes semanais. Os quartos eram localizados nos pavimentos superiores e não havia elevador. O restaurante era de cozinha internacional, com especialidade em pratos franceses. O restaurante era essencialmente freqüentado por moradores locais ou da região, enquanto o hotel era utilizado por visitantes que vinham a Santo André, sendo gerenciado pelo francês Gaston Le Doux, que foi trazido pelo proprietário para divulgar o empreendimento.

A sede deste hotel estava, portanto, estabelecida onde hoje se encontra a ACISA - Associação Comercial e Industrial de Santo André, defronte ao colégio Américo Brasiliense, região considerada nobre na década de 1950. O hotel pertencia a Hugo de Macedo e Blanche Marie Corcelette de Macedo, e foi adquirido por ambos em 1965, encerrando suas atividades poucos anos depois.

Em Santo André, não havia hotéis de grande porte e em virtude disto os executivos de grandes empresas não se hospedavam na região. A partir de 2001 é que os hotéis viriam efetivamente a se instalar na cidade de Santo André. Foram implantados quatro hotéis, três de grandes redes hoteleiras internacionais e um totalmente nacional e de administração particular.

\subsection{O Cenário da Região do Grande $\mathrm{ABC}$}

Na década de 1980, conforme destaca Klink (2001), retoma-se com maior vigor o debate no meio acadêmico sobre o papel ativo das cidades-regiões na economia mundial, e o espaço regional privilegiado para a criação de competitividade sistêmica e gestão pública compartilhada, a partir de uma série de experiências relevantes de reestruturação urbana, em especial na Europa e Estados Unidos. No caso brasileiro, a crise industrial tem expressivo impacto sobre a economia nacional, atingindo gravemente o tecido produtivo da região do Grande ABC, ao longo dos anos 1990.

O esforço de reestruturação realizado ainda naquela década incorpora uma série de novos estabelecimentos econômicos à referida região, com destaque para o comércio, em especial os shopping centers e hipermercados (inexistentes até então), possibilitando internalizar boa parcela do consumo dos seus próprios habitantes. Porém, a geração de empregos resultante 
desse esforço, centrada principalmente nos setores de comércio e serviços, não é capaz de promover o retorno aos níveis de emprego formal verificados anteriormente. Para Montagner e Bessa (2003), esses postos de trabalho foram parcialmente substituídos por novas ocupações como os prestadores de serviços para as empresas de atividade produtiva e por atuações mais vulneráveis como é o caso dos trabalhadores assalariados sem carteira assinada, trabalhadores autônomos juntos às empresas e contratos por tempo determinado.

Os empregos do setor de comércio e serviços, ao final dos anos 1980 são, em geral, em empresas de pequeno porte: comércios de rua ou pequenas lojas e mercados. Com o surgimento dos shoppings centers e dos hipermercados, surgiu a possibilidade da aquisição de bens de consumo no local de habitação, sem ter que se deslocar até São Paulo para consumir estes bens. Essa criação de novos comércios já não mais de pequeno porte e a substituição dos hábitos de lazer - refeições fora de casa, passeios ao teatro ou cinema, foram proporcionados pela própria estrutura que os shoppings centers oferecem. Verdadeiras ilhas de conforto dentro das grandes cidades ou regiões, como o Grande ABC. Desta maneira, a economia apresentava também os primeiros sinais de reaquecimento. Porém, ainda é a atividade industrial que determina o volume de negócios da economia local; por seu turno, se o setor de serviços não remunerava nos mesmos níveis que o setor industrial àquela época, cumpria seu valoroso papel à medida que dava início à recomposição dos níveis de emprego anteriores, e no período mais recente inclusive ultrapassando os patamares do começo dos anos 1990.

Para Daniel (2003), a crise nos municípios do Grande ABC foi acentuada desde os anos 1980 também pela guerra fiscal e pela conjugação de "forças centrífugas" no tecido social que inviabilizavam um projeto regional de reestruturação. Diante das alterações na região e ainda enfrentando muitos problemas, havia a alternativa de continuar a trabalhar de forma individual ou tentar aproximar as cidades e unir forças para o crescimento da região do Grande ABC. Esse conceito seria posto em prática logo depois, quando os governos de suas sete cidades $^{3}$ definem trabalhar de forma cooperativa, buscando executar ações e políticas públicas tendo como perspectiva a integração regional.

Em 1990, ocorre a criação do Consórcio Intermunicipal das Bacias do Alto Tamanduateí e Billings $^{4}$, associação dos sete municípios do Grande ABC, com o principal objetivo de

\footnotetext{
${ }^{3}$ A região do Grande $\mathrm{ABC}$, parte integrante da RMSP é composta pelos municípios de Santo André, São Bernardo do Campo, São Caetano do Sul, Diadema, Mauá, Ribeirão Pires e Rio Grande da Serra.

${ }^{4}$ Atualmente a entidade é conhecida e denominada Consórcio Intermunicipal do Grande ABC.
} 
representar seus consorciados em outras entidades, além de planejar e executar os projetos regionais para promover, melhorar e controlar a infra-estrutura urbana e o meio ambiente. Esta união de forças públicas e privadas é, de acordo com Cocco, Urani e Galvão (1999), o que pode efetivamente produzir e constituir cidadania em um dado território.

\subsection{O Projeto Eixo Tamanduatehy}

É no contexto de avanço da integração regional, já pela constituição da Câmara Regional do Grande $\mathrm{ABC}$, e de nova mudança na composição dos governantes eleitos na região, que surge o projeto Eixo Tamanduatehy, com o objetivo de recriar aquele vetor de desenvolvimento, frente às profundas transformações políticas, econômicas, tecnológicas e sociais que a região vinha sofrendo.

De fato, a partir do novo mandato do prefeito Celso Daniel em 1997, Santo André tem como uma das prioridades a articulação de propostas para o desenvolvimento urbano e econômico, com o projeto de construção de uma cidade "radicalmente democrática", contemplando toda a população com serviços e equipamentos públicos, melhorando a qualificação da força de trabalho e consequentemente intervindo no desenvolvimento local e regional.

Esta nova gestão tinha dentre suas propostas o desenvolvimento econômico municipal e regional como política ativa para o combate à crise e a retomada da geração de empregos; a participação popular por meio de canais democráticos vinculando a sociedade civil e o governo municipal; a melhoria da qualidade e eficiência dos serviços públicos; a construção de uma cidade agradável para os moradores, e a prioridade na educação.

Tendo em vista a melhoria dos equipamentos públicos, incorporada ao conceito do projeto Eixo Tamanduatehy (Figura 1) ${ }^{5}$, a cidade deveria oferecer aos seus moradores uma melhor qualidade de vida, estimulando no cidadão de Santo André o orgulho de ali viver. Foi contratado como consultor do projeto o urbanista Jordi Borja, responsável pela reestruturação da cidade de Barcelona e que trabalhara também nas cidades brasileiras de Recife, Salvador e São Paulo, juntamente com a arquiteta brasileira Raquel Rolnik.

\footnotetext{
${ }^{5}$ Vale assinalar que a Figura 1 não contempla empreendimentos e equipamentos que foram incorporados ao conceito do Eixo Tamanduatehy, alguns deles de grande impacto e já em fase de implementação, como o primeiro campus regional da Universidade Federal do ABC (UFABC), nas proximidades do hipermercado Carrefour.
} 


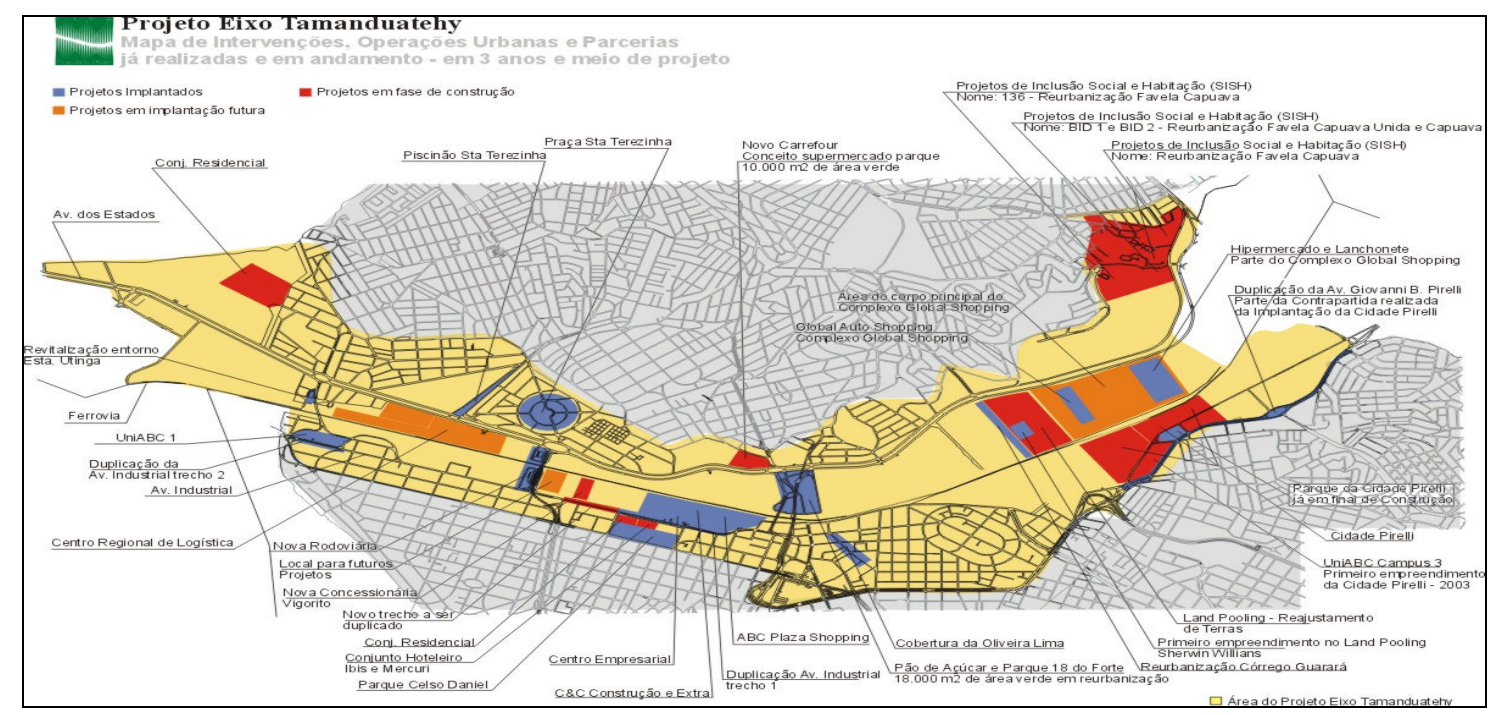

Figura 1 - Concepção Geral do Projeto Eixo Tamanduatehy

Fonte: Prefeitura Municipal de Santo André - Projeto Eixo Tamanduatehy. Disponível em: <www.santoandre.sp.gov.br>. Acesso em: 07 Abr 2007.

Após conhecer a realidade andreense, Borja propôs que se deixasse de lado o negativismo da saída das indústrias, para se pensar na positividade das áreas desocupadas e que poderiam ser revitalizadas com a instalação de equipamentos públicos, que além de melhorarem a qualidade de vida dos habitantes, também seriam uma alternativa econômica para as áreas de saúde, turismo, cultura e tecnologia (PREFEITURA MUNICIPAL DE SANTO ANDRÉ, 1999).

Na visão do referido urbanista, a situação de crise deveria ser revertida para uma oportunidade de crescimento. A cidade deveria se modernizar e tornar-se independente da cidade de São Paulo, através da oferta de serviços, cultura, universidades, comércio e núcleos residenciais. Assim sendo, um dos desafios, segundo Sakata (2006), era reunir um grupo que conseguisse administrar o projeto, e que cuidaria também do monitoramento das intervenções que deveriam ser feitas para que se concretizasse, e de fato uma série de avanços foram verificados no Eixo Tamanduatehy de 1998 a 2004.

Dentro das áreas do Projeto, muitas pertenciam a zonas residenciais ou zonas industriais. As operações urbanas são criadas mediante legislação específica, para permitir a construção de novos empreendimentos no lugar de antigos galpões industriais ou terrenos desocupados. $\mathrm{O}$ Eixo Tamanduatehy busca reorganizar as áreas periféricas ao rio do mesmo nome; algumas das áreas degradadas anteriormente, já reestruturadas, possibilitam melhor qualidade de vida 
dos cidadãos andreenses, através de novas possibilidades de comércio e serviços, com a conseqüente geração de empregos.

Dentro deste contexto, e conforme se apresenta na figura 2, surgem também dois novos hotéis, o Hotel Íbis e o Hotel Mercure. O Hotel Plaza Mayor, embora mais distante do perímetro do Eixo Tamanduatehy, também foi contemplado pela reurbanização da Rua Coronel Oliveira Lima, a principal via comercial do centro da cidade. Já o Hotel Quality Suites receberia autorização para se instalar na Avenida Portugal, que progressivamente se destacaria pela sofisticação dos empreendimentos comerciais e de serviços, em torno do Shopping ABC (ocupando a área do antigo Mappin) e de inúmeros laboratórios e clínicas de saúde, definindo-se, portanto, três localidades com posicionamento estratégico para os hotéis e para seus potenciais e efetivos usuários (como se pode comprovar cerca de uma década depois).
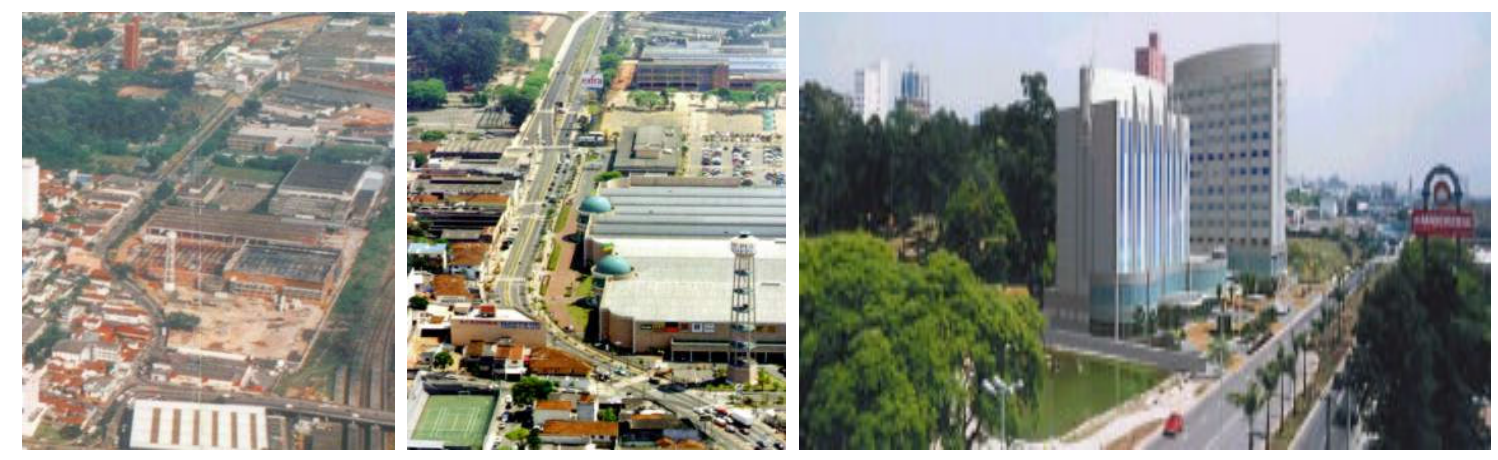

Figura 2 - A implantação de hotéis no Eixo Tamanduatehy

Fonte: Prefeitura Municipal de Santo André - Projeto Eixo Tamanduatehy. Disponível em: $<$ www.santoandre.sp.gov.br>. Acesso em: 07 Abr 2007.

Foto à esquerda: Avenida Industrial não duplicada observe-se área da antiga fábrica da Black \& Decker desativada no principio dos anos 1990. No fundo à esquerda, o Parque então denominado Duque de Caxias, atual Celso Daniel.

Foto central: Avenida Industrial já duplicada, com o Shopping ABC Plaza em planta térrea ocupando o local da antiga fábrica. À esquerda, no fundo, o mesmo Parque antes da instalação dos hotéis.

Foto à direita: Torres dos hotéis Ibis e Mercure ocupando área redestinada e contígua ao atual Parque Prefeito Celso Daniel.

\subsection{As Perspectivas dos Gestores Hoteleiros e dos Gestores Públicos}

A instalação de duas bandeiras hoteleiras (Mercure e Íbis), ambas da rede internacional Accor, mas atuando para públicos distintos num mesmo espaço foi uma decisão estratégica para alcançar economia de escala desde seus projetos de implantação, à medida que os dois hotéis puderam dividir algumas áreas e serviços comuns. Outro hotel situado em Santo André 
a partir de 2000, na Avenida Portugal como mencionado anteriormente, teve inicialmente a bandeira da rede Quality Suites, do grupo Atlantica Hotels International (AHI), sendo adquirido já no final de 2007 pela rede Blue Tree.

Por seu turno, o Hotel Plaza Mayor teve como fator de decisão o interesse do proprietário em investir em um hotel de maior porte na cidade. Para o Hotel Quality Suites foi decisiva a necessidade de novos empreendimentos, além de estabelecer a marca no Grande ABC. Para os representantes do poder público, a motivação principal da implantação dos hotéis na cidade se refere às transformações urbanas a partir de 1998 e à própria demanda latente que existia, criando a necessidade de ofertas hoteleiras.

Para três dos quatro novos hotéis instalados, a motivação do investimento deu-se ao fato de se verificar por meio de pesquisas de mercado, a necessidade de oferta de tipos diferentes de hospedagem, visto que muitos hóspedes da região do $\mathrm{ABC}$ optavam por hospedagem na cidade de São Paulo, especificamente, no bairro de Moema. Especificamente para um dos hotéis, o Plaza Mayor, como o proprietário já possuía um terreno disponível e outro hotel de menor estrutura na cidade, já conhecendo o potencial de demanda, a decisão foi eminentemente privada. De acordo com este gestor, as políticas públicas não foram fatores determinantes para a criação deste empreendimento. Foi a única das construções que não se utilizou de operações urbanas da prefeitura, já que pelas regras então vigentes poderia ser legalmente instalado um novo empreendimento hoteleiro.

Para o gestor do poder público, a instalação hoteleira também ocorreu por questões mercadológicas. Acredita-se que com a maior intensidade da globalização, as empresas passaram a dar enfoque às atividades fins, abrindo espaços para a terceirização, criando assim novos postos de trabalho para técnicos e operadores. Este intercâmbio, imigração e transferência de tecnologia fizeram com que se expandisse o turismo de negócios.

Para os hotéis que fazem parte do Projeto Eixo Tamanduatehy, houve motivação direta e as transformações seriam fatores determinantes para a tomada de decisão, principalmente, pela duplicação da Avenida Industrial, defronte ao atual Parque Prefeito Celso Daniel e ao Shopping Plaza ABC. Não fosse a ação do poder público, poderia não ter havido a vinda dos hotéis ou esta seria ainda mais tardia.

No caso do Hotel Plaza Mayor, a ação do poder público não interferiu e ainda não interfere, nas palavras de seu proprietário. Inclusive o gestor acredita que em muitas situações, por conta dos eventos, poderia ser feita alguma parceria no sentido de facilitar o embarque e 
desembarque de hóspedes e o fluxo do trânsito, a fim de tornar mais fácil a recepção de convidados. Já houve tentativas de parcerias neste sentido, porém não foram bem sucedidas. É interessante notar que há uma divergência de percepção entre gestores do poder público e do setor privados, pois os primeiros defendem que houve aumento do interesse pelo Turismo na cidade e os gestores privados afirmam que não houve interferência.

Nas quatro situações, o hotel foi criado para atender o público típico de turismo de negócios. Em virtude de haver muitas empresas na Região do ABC e na cidade de Santo André, para os investidores havia a necessidade de investimentos hoteleiros que pudessem atender desde os colaboradores técnicos até os empresários e visitantes estrangeiros. Este posicionamento quanto ao turismo de negócios, torna-se rentável também quando assume parceria com o turismo de eventos. Para os hotéis, muitas atividades acontecem em suas áreas de eventos e trazem hóspedes nacionais e internacionais.

Os hotéis executivos têm buscado alternativas na realização de eventos sociais para garantir sua ocupação nos finais de semana. Aparentemente, por meio das entrevistas com os gestores privados, apesar ainda de não acharem que o resultado econômico tivesse alcançado as expectativas, de maneira geral todos estão satisfeitos com a implantação. Procurou-se ainda saber destes gestores quais os aspectos mais favoráveis para o empreendimento, desde sua implantação. Como aspecto bastante favorável pode-se afirmar que houve maior visibilidade da cidade de Santo André, principalmente por se tratarem de redes internacionais, e colocando essa cidade e a região do Grande $\mathrm{ABC}$ no roteiro dos turistas de negócios.

Apesar de trabalharem com quadros de trabalhadores bastante comprometidos e fiéis, a criação simultânea dos novos empreendimentos hoteleiros tem levado a uma rotatividade de pessoal mais freqüente. Destina-se muito tempo para treinamento de pessoas e posteriormente estas pessoas vão treinadas para trabalhar em hotéis de rede, com o objetivo de terem um melhor plano de carreira. Essa é uma situação muito freqüente na hotelaria, principalmente nas grandes capitais, onde a demanda por pessoas capacitadas é ainda maior.

A pesquisa abordou também a ocorrência de eventos nos finais de semana na cidade de Santo André e em que medida estes eventos aumentam a taxa de ocupação. Estas respostas também foram divergentes entre o poder público e o setor privado. Para os gestores do poder público existem muitos eventos que aumentam a receita hoteleira, enquanto para os gestores privados estes eventos não interferem na taxa de ocupação. 
Os gestores hoteleiros são unânimes ao concordar que uma ação do poder público em conjunto com o setor privado, visando à criação de um espaço de eventos, atrairia muito mais turistas para a cidade; todavia, esses gestores têm pouco ou nenhum conhecimento sobre as atividades de turismo efetuadas pela cidade e pela região. Evidencia-se que o calendário de eventos do município e da região não tem sido divulgado de forma eficaz, restringindo a maior sinergia entre hotéis e poder público, e limitando o potencial econômico do turismo regional.

Eventos como o Festival do Chocolate em Ribeirão Pires, o Festival de Inverno de Paranapiacaba, os rodeios em Mauá e a Festa Italiana em São Caetano do Sul não são de conhecimento de todos os empreendimentos. Já para o gestor do poder público, alguns eventos são conhecidos fora da região e atraem público para a cidade. Pode-se perceber que as opiniões divergem novamente entre a gestão pública e o setor privado; esse tem a percepção de que os eventos não são divulgados, enquanto para o setor público eles têm um bom grau de conhecimento externo. Efetivamente, verifica-se que o evento pode ser conhecido, porém precisa ser consumido pelo público, e a partir das entrevistas com os hoteleiros isso não condiz com a realidade.

Os hotéis nutrem grande expectativa em relação à cidade de Santo André. Em relação às expectativas dos investidores para os próximos cinco anos, todos os hotéis almejam o aumento da taxa de ocupação, objetivo dos gestores e dos investidores. Os gestores públicos divergem dos privados ao afirmarem que há espaço para mais hotéis na cidade, o que para os gestores privados não se configura.

Após pesquisas internas, a Rede Accor constatou que quando há o aumento da procura por hospedagem nos hotéis de Moema (bairro da cidade de São Paulo), e estes não conseguem atender a demanda, os hóspedes são encaminhados para a Região do ABC. Sendo assim, realmente talvez os hoteleiros estejam certos e não haja mais espaço para ampliar a oferta hoteleira na região. Torna-se também clara a necessidade de dados quantitativos mais sistemáticos para comprovar a necessidade ou não de novos empreendimentos hoteleiros.

\section{Considerações Finais}

Este trabalho permitiu algumas reflexões acerca da reestruturação econômica da cidade de Santo André. No caso especifico do objeto de pesquisa, os hotéis que ocuparam os espaços anteriormente degradados vieram no processo de reurbanização e reorganização econômica da 
cidade e contribuíram com seu desenvolvimento, criando novos empregos e recebendo hóspedes, constituindo efetivamente um setor econômico relevante no município. De fato, dados do Observatório Econômico da própria prefeitura local apontam para um forte crescimento no emprego a partir das atividades de alojamento e alimentação, resultado também da expansão de restaurantes e bares de maior qualidade no município, com potencial e já real sinergia junto aos empreendimentos hoteleiros.

Os hotéis que não fazem parte do Eixo Tamanduatehy também colaboram de maneira positiva, na geração de ocupações e na oferta alternativa em locais também estratégicos no município. Notou-se também que a ação do poder público, principalmente durante a atuação do Prefeito Celso Daniel, foi muito consistente e importante para o desenvolvimento da cidade. Embora os gestores dos hotéis revelem ter pouco ou nenhum conhecimento sobre estes fatos, sem as ações do poder público a expansão hoteleira não teria ocorrido com a mesma intensidade.

Mesmo para os hotéis fora do Eixo Tamanduatehy, há o reflexo deste projeto. O Plaza Mayor está posicionado próximo da Rua Coronel Oliveira Lima, reestruturada para ser um shopping a céu aberto, inclusive com cobertura na maior parte da via. A revitalização deste espaço central da cidade foi muito importante para comerciantes e moradores das adjacências.

Para o Hotel Quality Suites, a acessibilidade proporcionada pela reestruturação urbanística também é positiva, especialmente pela modernização das atividades de comércio e serviços da Avenida Portugal. Embora o Shopping ABC e o Supermercado Eldorado tenham surgido antes da concretização do Projeto Eixo Tamanduatehy, já despontavam os sinais de que a cidade estaria cada vez mais envolvida com sua própria reestruturação econômica (transitando de predominantemente industrial para mista), com maior peso proporcional do comércio e do setor de serviços.

Também é inegável que a construção dos hotéis na Avenida Industrial causou impacto para os usuários do Parque Celso Daniel, principalmente no que diz respeito ao usuário freqüente, que alegam o bloqueio da luz solar pelas torres dos estabelecimentos, atingindo boa parte do parque. Apesar do setor de turismo ser comprovadamente um agregador de valor para a economia, percebe-se por esta pesquisa e outros trabalhos consultados, que este segue considerado como mera obra do acaso em muitas situações. Porém, o turismo é um setor da economia que merece um olhar ainda mais atento por parte do poder público, tanto nas esferas locais, regionais, estaduais e federais. Além disso, os indicadores públicos são ainda 
limitados, a informação hoteleira é embasada em fatores de interesse próprio, e as pesquisas sobre a hotelaria na Região do $\mathrm{ABC}$ e da cidade de Santo André são extremamente escassas.

Uma sociedade que não preserva sua memória, dificilmente consegue emergir para o progresso. Através de fatos sobre o passado pode-se evitar ou prevenir erros futuros. Hoje, embora não haja histórico hoteleiro, sabe-se que os hotéis estão se mantendo e se mostram bem sucedidos, com pouco tempo de operação. Assim sendo, este trabalho tem sua validade no sentido de auxiliar pesquisas futuras sobre o tema. A Região do ABC está inserida dentro de um contexto de história e desenvolvimento regional extremamente importante para o Brasil, tendo ainda diversas lacunas em sua investigação e análise.

O poder público argumenta que não há a união do trade turístico, enquanto esse argumenta que as ações do poder público são inexistentes ou ineficientes. No entanto, enquanto as duas esferas não dialogam se perdem grandes oportunidades, como o conceito de que a expansão hoteleira poderia ter surgido na década de 1960 ou 1970, concomitantemente ao auge da iniciativa privada industrial na região.

Verifica-se a necessidade de melhor compreender os movimentos sócio-econômicos regionais e assim motivar novas pesquisas sobre o turismo na região. Poderão ser objetos de futuras pesquisas os equipamentos de lazer e recreação (parques e estádios), alimentos e bebidas (restaurantes, buffets e churrascarias) e eventos (casas de shows e espaços de festas, feiras e reuniões). Este trabalho pode dar impulso a uma série de novas pesquisas sobre turismo na cidade de Santo André e no Grande ABC, podendo ainda ser objetos de estudo a hospitalidade, o lazer, a gastronomia e os eventos.

No decorrer do desenvolvimento deste trabalho, principalmente por meio das entrevistas e contatos com os hotéis e com o poder público, foi possível verificar o interesse demonstrado por cada entrevistado, pela própria carência de informações sobre o histórico da cidade no contexto do turismo, o que gerou grande expectativa em relação aos resultados da pesquisa. $\mathrm{O}$ entendimento da expansão hoteleira em um momento econômico como o atual é possível através de uma explicação embasada na cooperação entre o poder público e o setor privado. E essa situação poderá servir de exemplo para outras ações conjuntas desse tipo, em outras localidades do país. 


\section{Referências}

ADDIS, C. 1999. Taking the wheel: auto parts firms and the political economy of industrialization in Brazil. University Park: Pennsylvania State University Press.

BRUNO, F.; FELIPE, J.; DENALDI, R. 2006. Eixo Tamanduatehy. In: BARROS, C.; ARAÚJO, E. (Org.). Reabilitação urbana de centralidades metropolitanas: reflexões e experiências na América Latina do século 21. Recife: Prefeitura do Recife. Publicação da Unidade Temática Desenvolvimento Urbano - Rede Mercocidades.

COCCO, G.; URANI, A.; GALVÃO, A. 1999. Empresários e empregos nos territórios produtivos: o caso da Terceira Itália. Rio de Janeiro: DP\&A.

DANIEL, C. A. 2003. Ação política e diversidade de atores no universo social urbano. In: GONÇALVES, M. F. (org.). Regiões e cidades, cidades nas regiões. São Paulo: Unesp/Anpur.

KLINK, J. J. 2001. A cidade-região: regionalismo e reestruturação no Grande ABC paulista. Rio de Janeiro: DP\&A.

LANGENBUCH, J. R. 1971. A estruturação da Grande São Paulo: estudo de geografia urbana. Rio de Janeiro: Instituto Brasileiro de Geografia - Departamento de Documentação e Divulgação Geográfica e Cartográfica.

MONTAGNER, P.; BESSA, V. 2003. O comércio e os serviços no ABC: transformações e limites. Cadernos de Pesquisa. São Caetano do Sul, n. 8, p. 67-79, mar. 2003.

NOBRE E. A. C. 2000. Reestruturação econômica e território: expansão recente do terciário na marginal do Rio Pinheiros. 192 f. Tese (Doutorado em Arquitetura e Urbanismo) - Faculdade de Arquitetura e Urbanismo da Universidade de São Paulo, São Paulo.

PREFEITURA MUNICIPAL DE SANTO ANDRÉ. 1999. Disponível em: $<$ www.santoandre.sp.gov.br>. Acesso em: 07 abr. 2007. . 2004-2007. Boletim Econômico. (n. 1 a 16).

SABÓIA, J. 2001. Descentralização industrial no Brasil na década de 90: um processo dinâmico e diferenciado regionalmente. Nova Economia, Belo Horizonte, v.11, n.2, p. 85-122, dez. 2001.

SAKATA, M. N. 2006. Projeto Eixo Tamanduatehy: uma nova forma de intervenção urbana em Santo André? 244 f. Dissertação (Mestrado em Arquitetura e Urbanismo) - Faculdade de Arquitetura e Urbanismo da Universidade de São Paulo, São Paulo.

UVINHA, R. R. 2003. Turismo de aventura: uma análise do desenvolvimento desse segmento na Vila de Paranapiacaba. 178 f. Tese (Doutorado em Ciências da Comunicação) - Escola de Comunicação e Artes da Universidade de São Paulo, São Paulo.

\section{Recebido em: 30/11/2007 ( $1^{\text {a }}$ versão) $26 / 03 / 2008$ ( $2^{\mathrm{a}}$ versão) \\ Aprovado em: 31/03/2008}

